on those at high risk is adopted to the virtual exclusion of one based on population measures the impact on the community will be limited and bought at a high price. General practitioners and other doctors can contribute to population preventive efforts by helping all their patients to "take one small step to the left" on the distribution curve of risk of coronary heart disease.

\section{STEPHEN LEEDER} Professor MICHAEL GLIKSMAN

Research Fellow

Department of Community Medicine,

Westmead Hospital, Westmead,

New South Wales 2145,

Australia.
Beaglehole R, Dobson A, Hobbs MS, Jackson R, Martin CA. Coronary heart disease in Australia and New Zealand. In f Epidemiol 1989;18(suppl 1): 145-8.

Sytkowski PA, Kannel WB, D'Agostino RB. Changes in risk factors and the decline in mortality from cardiovascular disease. $N$ Engl f Med 1990;322:1635-41.

Al-Roomi KA, Dobson AJ, Hall E, Heller RF, Magnus P. Declining mortality from ischaemic heart disease and cerebrovascular discase in Australia. Am $\mathcal{F}$ Epidemiol 1989;129:503-10.

+ Keys A, Menotti A, Karvonen MJ, et al. The diet and 15-year death rates in the seven countries study. Am f Epidemiol 1986;124:903-15.

5 Gold $M$, Franks $P$. The social origin of cardiovascular risk: an investigation in a rural community. Int f Health Serv 1990;20:405-16.

6 Gliksman MD, Dwver T, Wlodarczyk J. Differences in modifiable cardiovascular disease risk factors in Australian schoolchildren: the results of a nationwide survey. Prev Med 1990;19:

Rose G. Sick individuals and sick populations. Int $\mathcal{f}$ Epidemiol 1985;14:32-8.

8 Gilksman MD, Dwyer T, Boulton TJC. Should the primary prevention of coronary heart disease commence in childhood? Med 7 A ust 1987;146:360-2.

9 McCormick J, Skrabanek P. Coronary heart disease is not preventable by population interventions. Lancel 1988;ii:839-41.

Lancel 1988;ii:839-41.
10 Syme SL. Coronary artery disease: a sociocultural perspective. Circulation 1987;76(suppl 1):112-6. 11 Hall J, Heller RF, Dobson AJ, Lloyd DM, Sanson-Fisher RW, Leeder SR. A cost-effectiveness analysis of alternative strategies for the prevention of heart disease. Med $\mathcal{F}$ Aust 1988;148:
273-7.

\title{
Clinical recognition of early invasive malignant melanoma
}

\section{Looking for changes in size, shape, and colour is successful}

The incidence of melanoma has risen by $80 \%$ in Scotland in the past decade (Scottish Melanoma Group registration figures, 1979-89), with similar rates of increase reported in many other countries. ${ }^{1}$ The outcome of disseminated melanoma is disappointing, and palliation rather than cure is all that can be achieved. If, however, stage I cutaneous melanoma is identified and excised when it has invaded less than $1 \mathrm{~mm}$ into the dermis the five year disease free survival figures are encouraging, at around $90 \%$. For this reason health education campaigns aimed at helping the public to identify possible early invasive malignant melanoma and seeking medical advice have been carried out in Europe and North America over the past five years. In Australia, the country with the highest incidence of melanoma in the world, they have been going on for the past two decades.

Public education campaigns need simple guidelines on what to look for in a pigmented lesion and what action to take if these features are identified. In early melanoma the guidelines need to encourage self referral with melanoma without unduly increasing referrals with the much more common benign pigmented cutaneous lesions such as banal pigmented naevi and seborrhoeic keratoses. Because of the seriousness of melanoma, however, the aim is that no early melanoma should be screened out on the basis of the advice offered. Thus sensitivity is more important than specificity and some element of overreferral is unavoidable. In the British health system guidelines also need to be made available to general practitioners, whereas in some other countries patients refer themselves direct to a specialist.

Our experience with public health campaigns dates from 1985, when we ran an early detection campaign for melanoma in the west of Scotland. ${ }^{3}$ Before any public education took place a booklet was circulated to all family doctors in the west of Scotland detailing the reason for the campaign and offering advice on lesions that should be referred. ${ }^{+}$This advice was based on seven features that, taken together, we had observed more commonly in melanoma than in non-melanoma pigmented lesions. The features characterise early invasive melanoma, not melanoma in situ, as the gold standard for accurate diagnosis remains histological examination of the excised specimen and not all pathologists agree on criteria for melanoma in situ or its prognostic importance and biological behaviour. The checklist is therefore based on a study of early but invasive level 2 or deeper lesions which, if not excised, are likely to progress.

For the 1985 campaign the seven points in the checklist were, in order: sensory change, often described as a greater awareness of the lesion but also as a mild itch; diameter of $1 \mathrm{~cm}$ or greater; growth of the lesion; an irregular edge; irregular pigment with different shades of brown and black in the lesion; inflammation (a reddish tinge within the lesion); and crusting, oozing, or bleeding. The advice offered to general practitioners was that, though referral of any pigmented lesion that was causing concern was welcome, in practice melanomas were likely to have three or more of these features, and that use of this checklist should help in selecting patients for referral.

Initial assessment of the value of this campaign was based on monitoring the thickness of all melanomas in patients living in Scotland, as this is the most accurate prognostic guide, and final assessment will be based on any observed changes in mortality. In the five years before 1985 melanoma thickness showed no significant change from year to year, but from 1986 onwards we have seen a significant shift in favour of thin lesions with a good prognosis. The numbers of melanomas continue to rise, but the number of thick lesions is unchanged, and the rise is confined to the thin group. ${ }^{3}$ In our own clinic for pigmented lesions, to which patients are referred by their family doctors, one melanoma is seen for every 20 nonmelanomas, and this ratio has also been reported in other pigmented lesion clinics in Britain. This contrasts with one melanoma for every 250 lesions examined in self referral clinics in the United States and one in 500 for a self referral free examination campaign conducted on Dutch beaches in 1989. Thus British general practitioners are excluding nonmelanomas with considerable skill.

More seborrhoeic keratoses are referred in Britain than in Australia, and as these often itch we thought that the position of itch as the first of the seven points-although logical as the only symptom - was perhaps attracting more attention than was warranted. In addition, in 1985-9 we observed a reduction not only in the depth of melanomas excised but also in their surface area and diameter. For these reasons and on the basis of 100 melanomas examined consecutively in this department in 1989 we revised the seven point checklist last year. ${ }^{5}$

The important point of the revision is that there are now 
Revised checklist for suspected malignant melanoma

Major signs

Minor signs

Change in size

Inflammation

Change in shape

Change in colour

Crusting or bleeding

Sensory change

Diameter $\geqslant 7 \mathrm{~mm}$

three major and four minor signs (see box). The major signschange in size, shape, and colour of a new or pre-existing cutaneous lesion - were seen in 94,95 , and 89 of the 100 lesions studied, and none failed to show one of the major signs. The 100 lesions included the elusive amelanotic, usually nodular, melanoma, which is often misnamed as most have a peripheral rim of pigment. Amelanotic melanomas are usually excised because of change in size or shape. The remaining four features -inflammation, crusting or bleeding, sensory change, and diameter (which has been reduced to 7 $\mathrm{mm}$ )-are found in combination more often than in nonmelanoma pigmented lesions, but they are less often present individually, with inflammation seen in 51 , sensory change in 46 , and crusting or oozing in 31 . Our current recommendation is, therefore, that a patient with a pigmented lesion with any one of the major signs should be considered for referral and that the presence of any of the minor signs should be a further stimulus to referral. It is also important to recognise that patients themselves may often not be aware of any of the six signs and that relatives or friends often note the changes and encourage consultation with the general practitioner. This is particularly true of men, possibly because the commonest site for melanoma in men is the back.

Once again I must emphasise that these are guidelines, and no lesions causing anxiety should be excluded from referral on the basis of this or any other checklist. It may well be easier, however, for family doctors themselves to offer reassurance on the basis of these guidelines, thus avoiding the need for referral.

The content of referral letters and purpose of the referral to our clinic has become much clearer over the past five years, and most letters now state concisely which features of the lesion have prompted referral, the patient's degree of concern,

and whether early melanoma is truly suspected or additional reassurance is the main purpose of referral. This allows accurate triage of referral letters at busy times, but even then no patient waits longer than three weeks to be seen. It remains to be established whether or not further refinements of this type of guideline can increase specificity with no loss of sensitivity in referral.

Additional aids to clinical recognition include the skin surface microscope or its less expensive cousin, the dermatoscope, and computerised image analysis. The first two instruments depend on recognising, in vivo, at moderate magnification, and under good lighting, features of the pigment distribution pattern in melanoma that are not seen in non-melanoma pigmented lesions. Over 25 years' personal experience with this suggests that the accuracy will not be greater than $85 \%,,^{67}$ a figure identical to that quoted recently by Grin et $a l^{8}$ for diagnostic accuracy based on clinical assessment. The use of computerised image analysis is being studied in several centres, and stored images will probably give a very good indication of change in a lesion previously assessed, such as a dysplastic naevus undergoing observation, though absolute diagnosis will be more elusive. Both the skin surface microscope and the computer are expensive and time consuming in use. They will therefore be found only in specialist centres, and simple guidelines such as the seven point checklist, revised and updated as new data become available, will continue to offer practice guidelines for the public and for family doctors.

Professor of Dermatology,

RONA M MACKIE

University of Glasgow,

Glasgow G11 6NU

1 Osterlind A, Jensen OM. Incidence of trunk melanoma in young Danish women. Br 7 Cancer 1987:55:467-72.

2 MCLeod GR. Control of melanoma in high risk populations. In: Elwood JM, ed Pigment cell. Vol 9. Basle: Karger, 1988:131-9.

Doherty VR, MacKie RM. Experience of a public education programme on early detection of cutaneous malignant melanoma. Br.Med f 1988;297:388-91.

Mac Kie RM. An illustrated guide to the recognition of early malignant melanoma. Glasgow: University Department of Dermatology, 1985

MacKie RM. Malignant melanoma. A guide to eurly diagnosis. (ilasgow: University Department of Dermatology, 1989.

6 MacKie RM. An aid to the preoperative assessment of pigmented lesions of the skin. Br 7 Dermatol 1971:85:232-8.

Anonymous. Skin surface microscopy. Anything new under the sun? [Editorial]. Lancet 1989;i:1239. 8 Grin CM, Kopf AW, Welkovich B, Bart RS, Levenstein MJ. Accuracy in the clinical diagnosis of malignant melanoma. Arch Dermatol 1990;126:763-6.

\section{Do streptococci cause toxic shock?}

\section{Possibly}

The toxic shock syndrome came to prominence as "tampon disease" and is caused by exotoxins of Staphylococcus aureus. Now a similar syndrome has been linked with erythrogenic toxin A of group A $\beta$ haemolytic streptococci. ${ }^{2}$. Of the three such toxins, toxin $A$ is particularly associated with the rash of scarlet fever. In recent decades it has been found infrequently in both Britain ${ }^{3}$ and the United States, ${ }^{+}$but it was present in strains originally isolated before the second world war. ${ }^{3}$ Can group A streptococci now produce toxin A more commonly, and does it produce toxic shock?

The decline in importance of group A streptococci in developed countries is usually attributed to improved social conditions and antibiotics, but changes in the distribution of serotypes and in toxin production may also have played a part. ${ }^{5}$ Recent events in streptococcal disease demonstrate this and do not allow complacency. Outbreaks of rheumatic fever in the United States have been associated with $M$ type 18, still not a common serotype. In 1988 notifications of scarlet fever in Britain rose, as did the incidence of the associated $M$ type 4 among strains sent to the Streptococcus Reference Laboratory. ${ }^{6}$ The number of group A strains isolated from patients with bacteraemia by the laboratory in 1975-88 increased in parallel with the general increase in reporting of positive blood cultures.

The two clinical reports of toxic shock syndrome apparently associated with group A toxin A are suggestive: among the 22 patients with serious documented group A streptococcal infection, 21 were hypotensive, 18 had renal impairment, and seven died. ${ }^{12}$ Nine of the 12 strains examined produced toxin A. This was not a point source outbreak as different serotypes 